Original Research Paper

\title{
Identification of Molecular Markers Differentiating Betula papyrifera and B. pumila Populations from Northern Ontario (Canada)
}

\author{
${ }^{1}$ Nastaran Moarefi, ${ }^{2}$ Paul Michael, ${ }^{1}$ Peter Beckett and ${ }^{1,2}$ Kabwe Nkongolo \\ ${ }^{I}$ Department of Biology, \\ ${ }^{2}$ Biomolecular Sciences Program, \\ Laurentian University, Sudbury, Ontario, Canada, P3E 2C6, Canada
}

Article history

Received: 20-09-2018

Revised: $29-10-2018$

Accepted: 29-11-2018

Corresponding Author:

Kabwe Nkongolo

Department of Biology,

Laurentian University,

Sudbury, Ontario, Canada, P3E

2C6, Canada

Email: knkongolo@laurentian.ca

\begin{abstract}
Betula is a polyploid and highly polymorphic genus with several species known to hybridize very readily. This high level of introgression has resulted in hybrid populations where different species are sympatric. The main objectives of the present study were to identify putative hybrids between $B$. papyrifera and B. pumila in the Greater Sudbury Region (Northern Ontario) and to develop ISSR and RAPD markers that can differentiate $B$. papyrifera and $B$. pumila and their respective populations. This study revealed extensive introgression of $B$. papyrifera genes into $B$. pumila based on morphological characterization in the Greater Sudbury region (Northern Ontario) where these two species coexist. Genomic DNAs were extracted from all the collected genotypes from seven $B$. papyrifer $a$ and five $B$. pumila populations within the GSR. Additional samples from $B$. pumila from Wisconsin were also analyzed. All the DNA samples were amplified using ISSR and RAPD primers. No species - diagnostic markers was identified because in part to a high level of polymorphic loci observed within and among populations. A close look of all the amplified products revealed a number of ISSR and RAPD diagnostic markers that differentiate $P$. papyrifera populations from different origins. Likewise, diagnostic bands distinguishing B. pumila from Wisconsin to the GSR population were identified.
\end{abstract}

Keywords: Betula papyrifera, B. pumila, ISSR, RAPD, Northern Ontario

\section{Introduction}

Betula is a polyploid and highly polymorphic genus with several species known to hybridize very readily. This high level of introgression has resulted in hybrid populations where different species are sympatric (Woodworth, 1929; Anamthawat-Jonsson and Thorsson, 2003). Hybrids between Betula pumila X Betula lenta, Betula populifolia X Betula papyrifera, Betula uerrucosa $X$ Betula papyrifera and others have been reported (Froiland, 1952). The morphological variation in putative hybrids makes it difficult to differentiate them from their parental species on the basis of characters normally used in identification.

Bog Birch (B. pumila) typically inhabits wetland environments. It can also be found in low areas of sand dune habitats. This species is vulnerable to invasive species. It is typically a 1.8 to $2.5 \mathrm{~m}$, densely multistemmed shrub but can be highly variable in leaf characters and height. It readily hybridizes with $B$. alleghaniensis and $B$. papyrifera resulting in $B$. $\mathrm{x}$ purpusii and $B . \mathrm{x}$ sandbergii, respectively. These hybrids are known to further cross and backcross producing potentially a myriad of intermediate characteristics. Most of these hybrids are over $3.5 \mathrm{~m}$ and look more tree than shrub (NOF, 2018).

White birch (Betula papyrifera), the most widely distributed (east to west) of all North American birches is primarily native to the cold climates of Canada and Alaska, with its range dipping down into a few of the northern U.S. states and further south in the mountains (to Colorado in the Rockies and to North Carolina in the Appalachians) (Uchytil, 1991). It is a small to mediumsized tree, often with many stems, up to $30 \mathrm{~m}$ tall. It grows on a variety of soils and is abundant on rolling upland terrain and floodplain sites, but it also grows on open slopes, avalanche tracks, swamp margins and in bogs. It doesn't grow well in shade and consequently it 
often occurs in younger forests following a disturbance (Uchytil, 1991; Theriault et al., 2013).

This open pollinated species is dominant in the Greater Sudbury Region in Northern Ontario (Canada) after land reclamation. In fact, this species represents $65 \%$ of all trees in the region (Theriault et al., 2013). It produces male and female flowers on the same tree in the form of catkins. Both male and female catkins lack petals enhancing B. papyrifera pollination with $B$. pumila flowers within the same stand. It has been hypothesized that the exchange of genetic information between Betula papyrifera and other species within the genus Betula might be a common phenomenon in open populations (Sofiev et al., 2006; 2013; Theriault et al., 2014). This should result in characteristics that are variable within species making the identification of pure and hybrid genotypes very challenging. Hence, development of species and population diagnostic molecular markers would be useful. It is also important to determine the genetic status of tree populations growing in specific ecological conditions for adaptations and reclamations purposes.

In the last few decades, Inter-Simple Sequence Repeat (ISSR) and Random Amplified Polymorphic DNA (RAPD) markers and other DNA technologies have been employed to analyze genetic structure of populations of several forest trees and to delineate species. DNA markers have successfully distinguished plant species and crop varieties (Mei et al., 2015). Nkongolo et al. (2005) and Mehes-Smith et al. (2007) used ISSR and RAPD marker systems to distinguish conifer species such as $P$. glauca and $P$. engelmannii, $P$. mariana and $P$. rubens, Pinusstrobus and Pinus monticola from one another. But these markers have never been developed in hardwood species such as Betula.

The main objectives of this project were to identify putative hybrids between B. papyrifera and B. pumila in the GSR and to develop ISSR and RAPD markers that can differentiate $B$. papyrifera and B. pumila and their respective populations.

\section{Materials and Methods}

\section{Sampling}

Fresh B. papyrifera, B. pumila and putative hybrid leaf samples were collected from the targeted sites within the Greater Sudbury Region (GSR) based on leaf morphology. Five sites were selected for B. papyrifera (Capreol, St. Charles, Onaping Falls, Airport and Azilda) and six for $P$. pumila and potential putative hybrids samples collection (four populations from Boreal College site, one from Lasalle site and one from Lasalle extension site) (Fig. 1). Ten trees representing each population were selected for this investigation. Leaf samples were wrapped in aluminum foil, immersed in liquid nitrogen and stored at $-20^{\circ} \mathrm{C}$ until DNA extraction.
Additional samples for $B$. pumila collected from Wisconsin (USA) were provided as seeds (Lot number 1819892) by the Sheffield Seed Company, New York, USA. These seeds were grown in Petawawa boxes as described in Nkongolo et al. (2005) and the DNA was extracted from three weeks old seedlings.

\section{Molecular Analysis}

Total DNA was extracted from fresh frozen leaf material using the CTAB extraction protocol as described by Theriault et al. (2013) and Kalubi et al. (2015). This is a modified Doyle and Doyle (1987) procedure that included the addition of $1 \%$ Polyvinyl Pyrrolidone (PVP) and $0.2 \%$ beta mercaptanol to the cetyl trimethylammonium bromide (CTAB) buffer solution, two additional chloroform spins prior to the isopropanol spin and no addition of RNAse. After extraction, DNA was stored in a freezer at $-20^{\circ} \mathrm{C}$.

A total of 34 ISSR and 18RAPD primers synthesized by Invitrogen were chosen for DNA amplification. PCR analysis was carried out following the procedure described by Vaillancourt et al. (2008) and Theriault et al. (2013). Each PCR reaction was performed using a total of $25 \mu \mathrm{l}$ volumes which contained in a $25 \mu \mathrm{L}$ total volume containing a master mix of $11.4 \mu \mathrm{L}$ distilled water, $2.5 \mu \mathrm{L} \mathrm{MgSO}_{4}, 2.1 \mu \mathrm{L} \mathrm{10x}$ buffer $0.5 \mu \mathrm{L}$ of dNTPs (equal parts dTTP, dATP, dCTP, dGTP), $0.5 \mu \mathrm{L}$ of ISSR primer, a Taq mix of $3.475 \mu \mathrm{L}$ distilled water, $0.4 \mu \mathrm{L} 10 \mathrm{x}$ buffer and $0.125 \mu \mathrm{L}$ Taq polymerase (Applied Biosystems) and $4 \mu \mathrm{L}$ standardized DNA. For each primer, a negative control reaction was included where $\mathrm{ddH}_{2} \mathrm{O}$ was added instead of DNA. All samples were covered with one drop of mineral oil to prevent evaporation and amplified with the Eppendorf Mastercycler gradient. The program was set to a hot start of $5 \mathrm{~min}$ at $95^{\circ} \mathrm{C}$ followed by $2 \mathrm{~min}$ at $85^{\circ} \mathrm{C}$ during which the Taq mix was added, then 42 cycles of $1.5 \mathrm{~min}$ at $95^{\circ} \mathrm{C}, 2$ min at $55^{\circ} \mathrm{C}$ and one minute of $72^{\circ} \mathrm{C}$. A final extension of $7 \mathrm{~min}$ at $72^{\circ} \mathrm{C}$ after which samples were removed from the thermocycler and placed in the $-20^{\circ} \mathrm{C}$ freezer until further analysis. All PCR products were loaded into $2 \%$ agarose gel in $0.5 \mathrm{X}$ Tris-Borate-EDTA (TBE) buffer. After the DNA samples were amplified, they were separated for analysis on a $2 \%$ agarose gel in $0.5 \mathrm{x}$ TBE with ethidium bromide and run at $3.14 \mathrm{~V} / \mathrm{cm}$.

Five $\mu \mathrm{L}$ of $1 \mathrm{x}$ loading buffer were added to the PCR products and $10 \mu \mathrm{L}$ of this solution were loaded into the wells of the gel. The gel was run as described above, documented with the Bio-Rad ChemiDoc XRS system and analyzed with Image Lab Software. Only the ISSR and the RAPD primers which gave consistent profiles across the populations and also those that appeared to have diagnostic markers were selected for further analysis. The presence and absence of bands were scored as 1 or 0 , respectively. Faint bands were not recorded for analysis. 


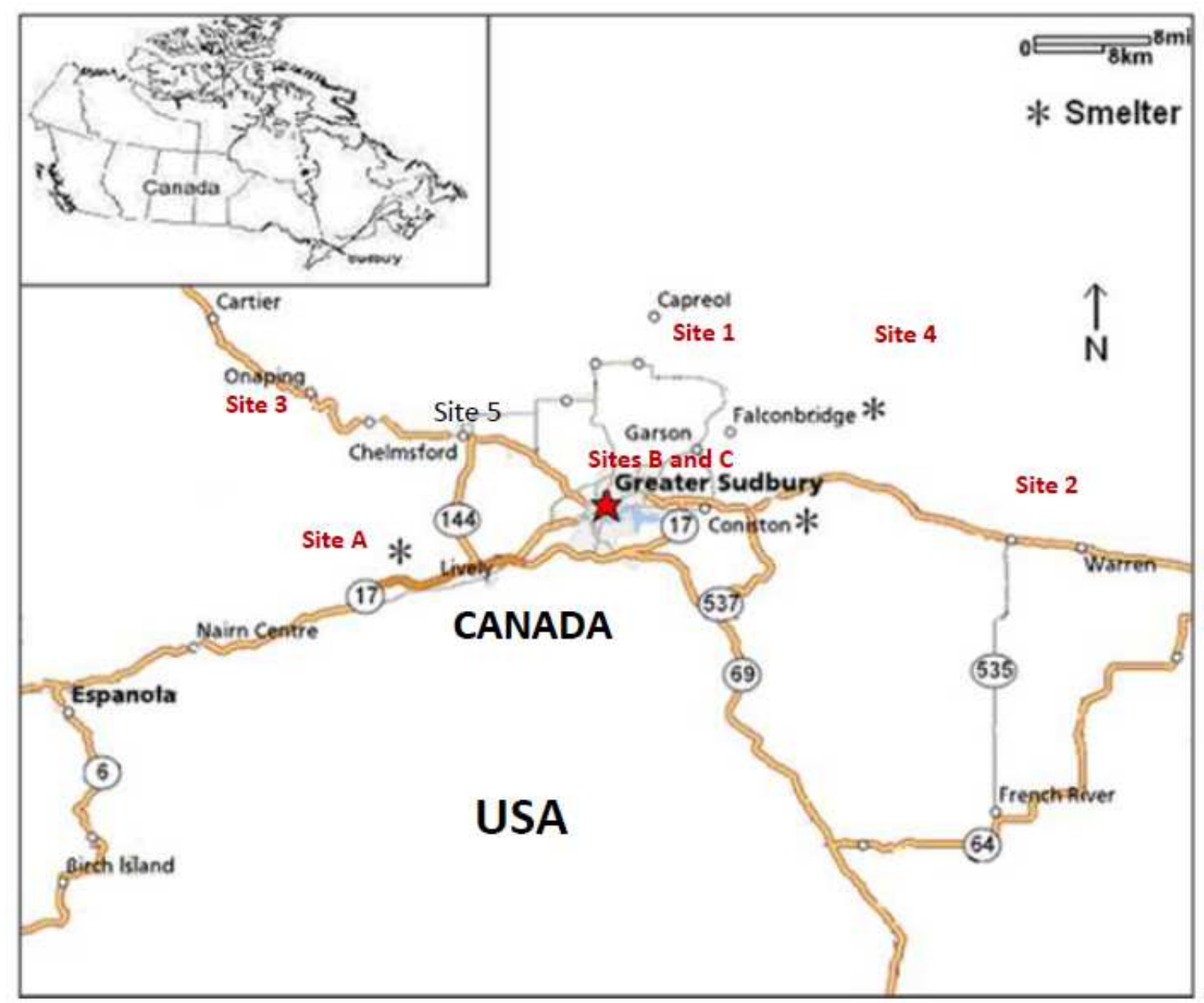

Fig. 1: Locations of the soil sampling areas from the Greater Sudbury Region for Betula papyrifera, the sampling sites include Site 1: Capreol (reference); Site 2: St. Charles (reference); Site 3: Onaping Falls (reference); Site 4: Airport; Site 5: Azilda. Locations for Betula pumila and putative hybrids include site A (Sudbury Lasalle extension), site B (College Boreal) and site $\mathrm{C}$ (Lasalle cemetery area).

\section{Results and Discussion}

\section{Ecological Analysis}

Pure B. papyrifera stands were easy to identify within the GSR based on morphological characteristics. However, P. pumila stands showed variations in genotypes varying from pure $B$. pumila shrubs to putative $P$. papyrifera $x P$. pumila hybrids. We found five such putative stands within the vicinity of pure B. papyrifera populations at four sites (three at "College Boreal" and one at Lasalle site). This suggests that the pollen from $B$. papyrifera did fertilize readily with $B$. pumila female flowers. In all the cases, the putative hybrids showed intermediate characteristics for heights but the leaves size and shapes varied ranging from intermediate between $B$. papyrifera and $B$. pumila to similar to B. papyrifera (Fig. 2 and 3). B. pumila populations from wetland sites (One at College Boreal and one at Lasalleextention) that were isolated exhibited characteristics of true B. pumila species.

Cytological characteristics can be used as a tool for species identification in some cases. Chromosome number in Betula genus varies considerably within the species. The somatic chromosome diploid number for $B$. papyrifera is 70 or 84 , rarely 56 . For $B$. pumila, somatic chromosome number is usually $2 \mathrm{n}=56$ (Les, 2017). Hence, putative hybrid between $B$. pumila and $B$. papyrifera can be assessed based on chromosomes number and morphological features. In other species, pentaploids $(2 \mathrm{n}=70)$ hybrids known as $B$. x purpusil occur between B. pumila and B. alleghaniensis where the two species are sympatric. Likewise, $B . x$ sandbergii are hybrids between B. pumila and B. papyrifera and can be found where these species coexist. Both hybrids are considered obligate aquatics. 


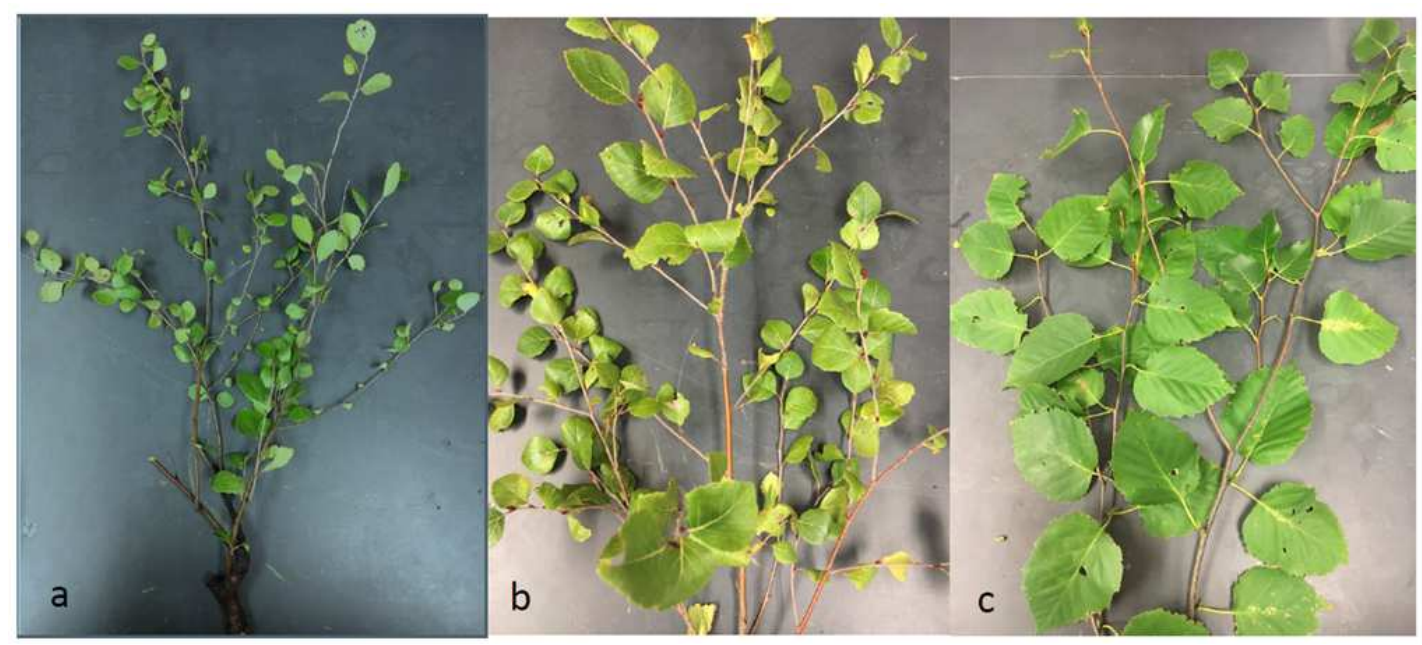

Fig. 2: Betula samples collected from the Greater Sudbury Region; Betula pumila on the left (a), putative hybrid in the middle (b) and Betula papyrifera on the right (c)

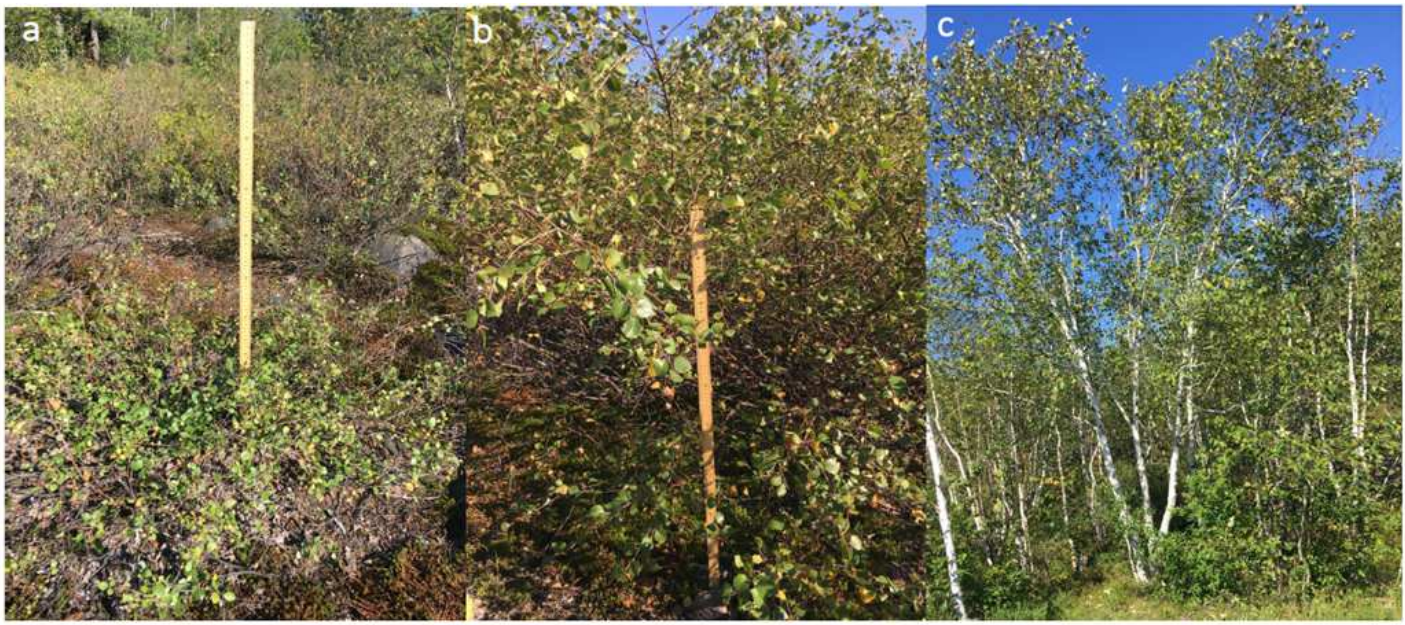

Fig. 3: Field view of Betula pumila on the left (a), putative hybrid in the middle (b) and Betula papyrifera on the right (c)

It is known that hybridization in the genus Betula is a common phenomenon (Reznicek et al., 2011). For example, B. papyrifera hybridizes naturally with almost every other native species in the genus (Barnes et al., 1974; Clausen, 1962; Little, 1979; Viereck et al., 1983; Thorsson et al., 2001). Hybrids between B. papyrifera and shrub or small tree species include Yukon birch (B. $x$ eastwoodiae Sarg. or B. x commixta Sarg.) with resin birch (B. glandulosa); horne birch (B. $x$ hornei Butler or $B$. $x$ beeniana A. Nels.) with dwarf $\operatorname{arctic} \operatorname{birch}(B$. nana); Sandberg birch (B. $x$ sandbergii Britton or $B$. $x$ uliginosa Dugle) with bog birch (B. pumila var. glandulifera); and Andrews birch (B. $x$ andrewsii A. Nels. Or B. $x$ piperi Britton or B. $x$ utahensis Britton) with water birch (B. occidentalis). The variety cordifolia is thought to be a hybrid of paper (B. papyrifera) and yellow birch (B. alleghaniensis). Blue $\operatorname{birch}(B . x$ caerulea or $x$ caerulea-grandis) is a hybrid between grey birch and var. cordifolia (Brittain and Grant, 1967; Grant and Thompson, 1975). B. X caerulea is derived from $B$. papyrifera $x B$. populifolia. The hybrids between $B$. papyrifera and sweet (B. lenta) and river (B. nigra) birch have not been named.

Some studies have reported the usefulness of pollen morphology in birch taxonomy. Differences in pollen mean size, relative size of vestibulum and minor structural characteristics of pores have been key features of birch species identification (Blackmore et al., 2003; Karlsdóttir et al., 2008). Hence, pollen characteristics can be used to assess the introgression levels between Betula species. But, Ives (1977) who attempted to differentiate Betula nana, Betulaglandulosa and Betula papyrifera based on pollen morphology was not able to separate them one from another because their pollen size characteristics form a morphological continuum. Since it is still not easy to differentiate Betula populations within 
the same species using morphological, cytological and pollen characteristics, other methods have to be considered. Our focus therefore was to explore the use of molecular tools to differentiate B. papyrifera, B. pumila and their putative hybrids from the GSR.

\section{Molecular Analysis}

All the genomic DNA samples were tested to assess their degradation level. They were run in a $1 \%$ agarose gel with $0.5 \mathrm{x}$ TBE (Tris-Borate-EDTA) buffer. All DNA samples showed large molecular weight bands at the top of the gel. This indicated that they were not degraded and were suitable for PCR amplifications.

The ISSR and RAPD primers used are described in Table 1. Out of the 52 primers screened, 22 ISSR and 8 RAPD primers generated amplification products. The level of polymorphic loci between species was around $98 \%$. This level of intra - population polymorphism was $>75 \%$ for the selected primers. Figure 4 and 5 depict an ISSR and a RAPD profile showing this high level of polymorphism. Theriault et al. (2013) reported a level of polymorphism ranging from $30 \%$ to $79 \%$ among $B$. papyrifera populations from the GSR. However, the primers and some of the populations used were not the same as in the present study. Hao et al. (2015) revealed that polymorphic frequency of the alleles ranged from $17 \%$ to $100 \%$ with a mean of $55.85 \%$ in B. papyrifera populations they analyzed using SSR (microsatellite) primers. Tran et al. (2014) reported a level of polymorphic loci ranging from $44 \%$ to $65 \%$ with ISSR primers and $61 \%$ to $72 \%$ with RAPD primers for Quercusrubra from the GSR. Kalubi et al. (2015) reported a polymorphism from $51 \%$ to $67 \%$ in $A$. rubrum from the GSR based on ISSR analysis. No species diagnostic ISSR or RAPD markers could be identified because in part of the high level of genetic variation observed in the present study. This lack of differentiation between the two species can also be attributed to the high level of gene integration between them.

A close look of all the amplified products revealed population - diagnostic markers that differentiate the $P$. papyrifera populations from St Charles from other populations. Likewise, diagnostic markers distinguishing B. pumila from Wisconsin and Sudbury were identified.

RAPD primer (RAPD UBC 402) revealed a population diagnostic marker for Betula pumila whereas four ISSR primers (SC ISSR 10, ISSR UBC 844, ISSR UBC 827 and ISSR HB 12) generated population diagnostic markers for both B. pumila and B. papyrifera. Some populations - diagnostic markers are illustrated in Fig. 6 to 8. For Betula papyrifera, primer SC ISSR 10 generated diagnostic markers of $\sim 550 \mathrm{bp}$ and $475 \mathrm{bp}$ differentiating the St. Charles population from other samples from the GSR (Fig. 6). It also generated a diagnostic marker $(\sim 750 \mathrm{bp})$ distinguishing B. pumila from Sudbury from Wisconsin's. The ISSR UBC 827 primer amplification profile showed three markers of $\sim 550 \mathrm{bp}, \sim 600 \mathrm{bp}$ and $\sim 750 \mathrm{bp}$.that distinguish St Charles population from other samples. It generated a marker ( 700 bp) that differentiated B. Pumila from Wisconsin and Sudbury. Other markers depicting differences between St Charles population with other populations include ISSR UBC 844 ( $\sim 525 \mathrm{bp}, \sim 550$ bp and $\sim 400 \mathrm{bp}$ bands) and ISSR HB12( $\sim 850 \mathrm{bp}, \sim 650 \mathrm{bp}$ and $\sim 475 \mathrm{bp})$. These two primers (ISSR UBC 844 and ISSR HB12) amplified also PCR products of $\sim 575 \mathrm{bp}$ and $\sim 1200 \mathrm{bp}$ that distinguish $B$. pumila population from Wisconsin from the Sudbury's (Fig. 7).

Table 1: Nucleotide sequence of ISSR and RAPD primers used on B. papyrifera and B. pumila populations

\begin{tabular}{llc}
\hline Primers & Primer sequence (5'-3') & G + C content (\%) \\
\hline ISSR primers & & 72.73 \\
ISSR HB 12 & CAC CACCAC GC & 72.73 \\
ISSR HB 13 & GAG GAGGAG GC & 52.94 \\
ISSR UBC 827 & ACA CAC ACA CAC ACA CG & 44.44 \\
ISSR UBC 834 & AGA GAG AGA GAG AGA GYT & 50.00 \\
ISSR UBC 835 & AGA GAG AGA GAG AGA GYC & 50.00 \\
ISSR UBC 844 & CTC TCT CTC TCT CTC TRC & 50.00 \\
ISSR UBC 873 & GAC AGA CAG ACA GAC A & 50.00 \\
ISSR 17898A & CAC ACA CAC ACA AG & 69.23 \\
SC ISSR 3 & GAC GACGACGAC G & 51.42 \\
SC ISSR 10 & CTT CTTCTTCTTCTT CCT CCTCCTCCTCCTCCT CT \\
RAPD primers & & 70.00 \\
RAPD Grasse 2 & GTG GTC CGC A & 90.00 \\
RAPD Grasse 3 & GTG GCC GCG C & 80.00 \\
RAPD Grasse 4 & GAG GCG CTG C & 80.00 \\
RAPD Grasse 5 & CGC CCC CAG T & 90.00 \\
RAPD UBC 270 & TGC GCG CGG G & 70.00 \\
RAPD UBC 337 & TCC CGA ACC G & 80.00 \\
RAPD UBC 402 & CCC GCC GTT G & \\
\hline
\end{tabular}




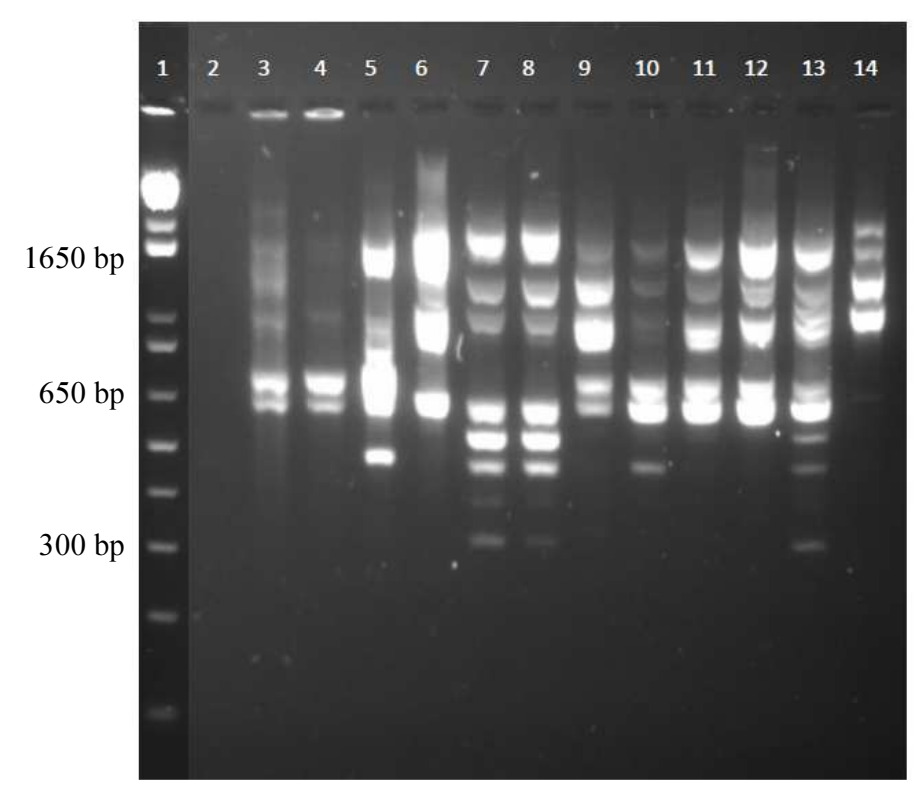

Fig. 4: Primer SC ISSR 10 amplified profiles of genomic DNA from Betula papyrifera and Betula pumila in 2\% agorose gel. Where lane 1 is the $1 \mathrm{~Kb}+\mathrm{DNA}$ ladder, lane 2 is the blank, lane 3 is $B$. pumila from Wisconsin, lane 4 is B. pumila from Wisconsin. Lanes 5-14 represent B. papyrifera (where lanes 5-6 are samples from Capreol, lanes 7-8 from St. Charles, lanes 9-10 from Onaping Falls, lanes 11-12 from are Airport and lanes 13-14 from Azilda). Note the distinct profiles of St. Charles samples (lanes 7 and 8)

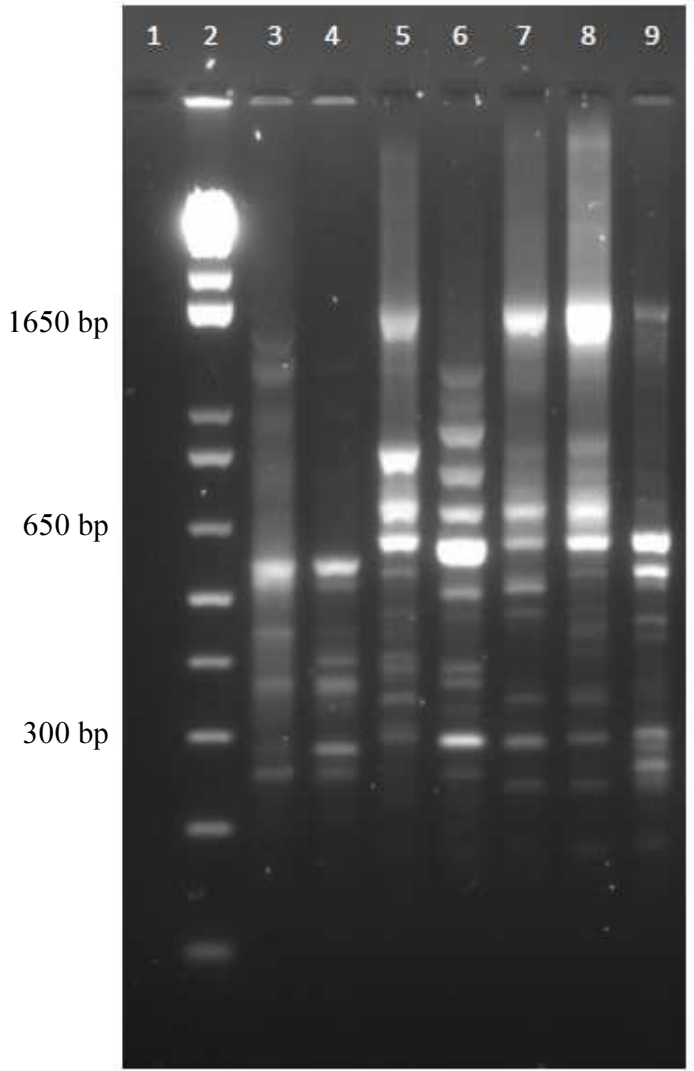

Fig. 5: Primer RAPD UBC 270 amplified profiles of genomic DNA from Betula papyrifera and Betula pumila in $2 \%$ agorose gel; Where lane 1 is the blank, lane 2 is the $1 \mathrm{~kb}+$ DNA ladder. Lane 3 and 4 are B. pumila from Wisconsin; Lanes 5-9 represent B. papyrifera samples (where lane 5 are samples from Capreol, lane 6 from St. Charles, lane 7 from Onaping falls, lane 8 from Airport, lane 9 from Azilda). Note the distinct profile of St. Charles sample (lanes 6). 


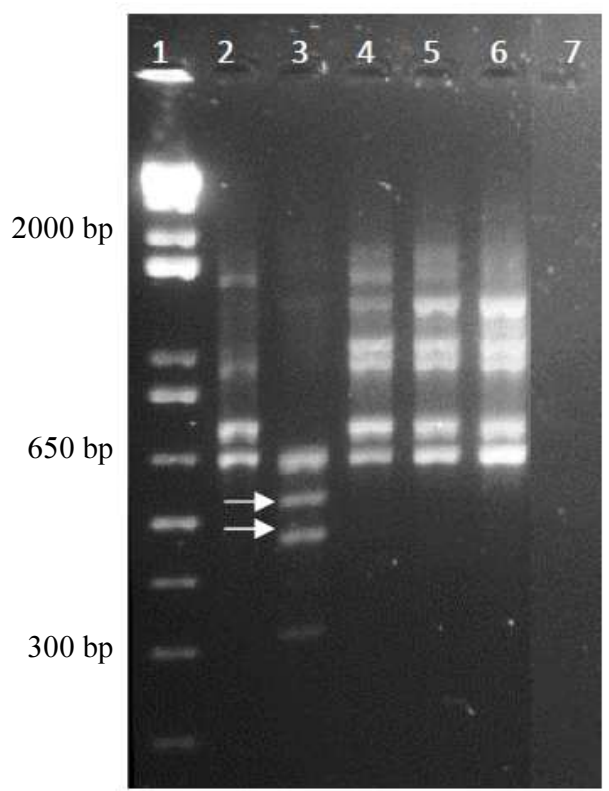

(a)

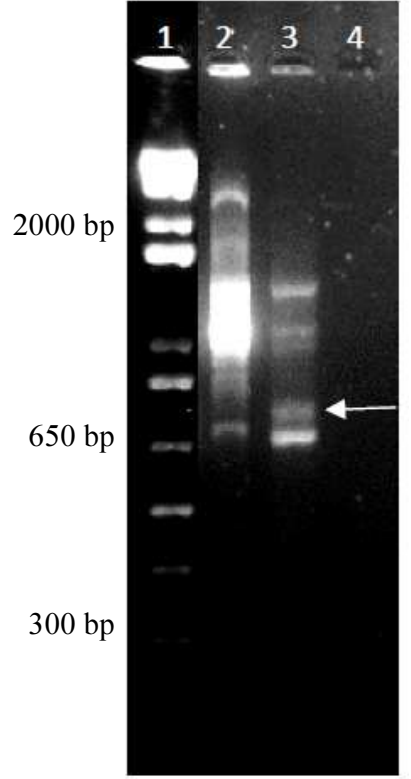

(b)

Fig. 6: Primer SC ISSR 10 amplified profiles of genomic DNA from Betula papyrifera and Betula pumila in 2\% agarose gel; (a) Where lane 1 is the $1 \mathrm{~Kb}+$ DNA ladder and lanes 2-6 represent amplified pooled DNA from B. papyrifera (where lane 2 are samples from Capreol, lane 3 from St. Charles, lane 4 from Onaping falls, lane 5 from Airport, lane 6 from Azilda). Lane 7 is the blank. The arrows show population - diagnostic bands for St. Charles (lane 3 ) in B. papyrifera. b) Lane 1 is the $1 \mathrm{~kb}+$ DNA ladder, lane 2 represents amplified pooled B. pumila DNA from Sudbury, lane 3 is the amplified pooled B. pumila DNA from Wisconsin USA (lot number: 1819892) and lane 4 is the blank. The arrow reveals a population-diagnostic band for B. pumila from Wisconsin (lane 3)

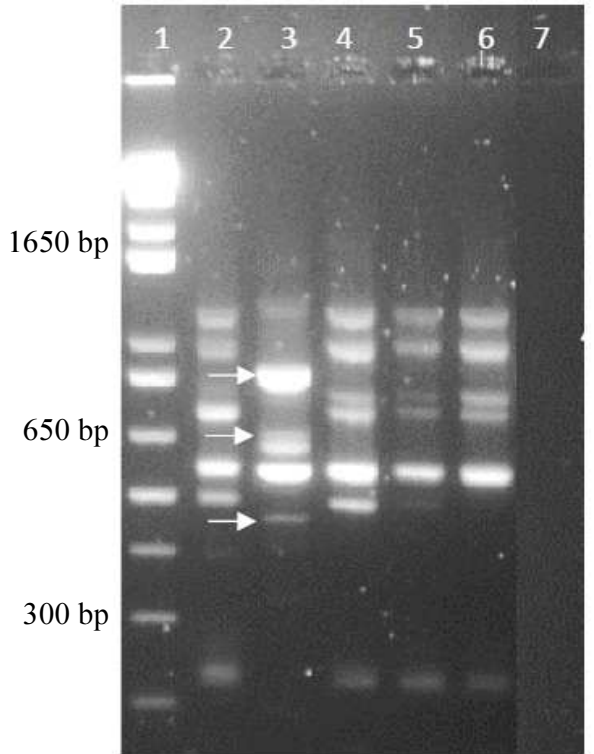

(a)

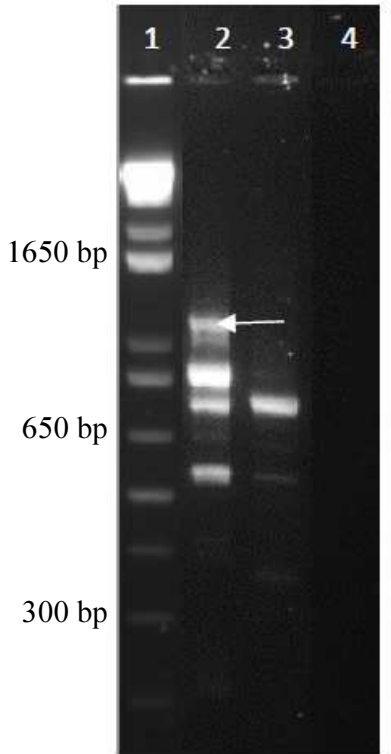

(b)

Fig. 7: Primer ISSR HB12 amplified profiles of genomic DNA from Betula papyrifera and Betula pumila in 2\% agorose gel; (a) Where lane 1 is the $1 \mathrm{~kb}+$ DNA ladder. Lanes 2-6 represent the amplified pooled DNA from B. papyrifera (where lane 2 are samples from Capreol, lane 3 from St. Charles, lane 4 from Onaping falls, lane 5 from Airport, lane 6 from Azilda. Lane 7 is a blank. The arrows reveal population diagnostic bands for St. Charles (lane 3) in B. papyrifera. (b) Where lane 1 is the $1 \mathrm{~kb}+\mathrm{DNA}$ ladder. Lane 2 represents amplified pooled B. pumila DNA from Sudbury and lane 3 is amplified pooled B. pumila DNA from Wisconsin USA (lot number: 1819892). The arrow shows a population-diagnostic band for B. pumila Sudbury (lane 2) 


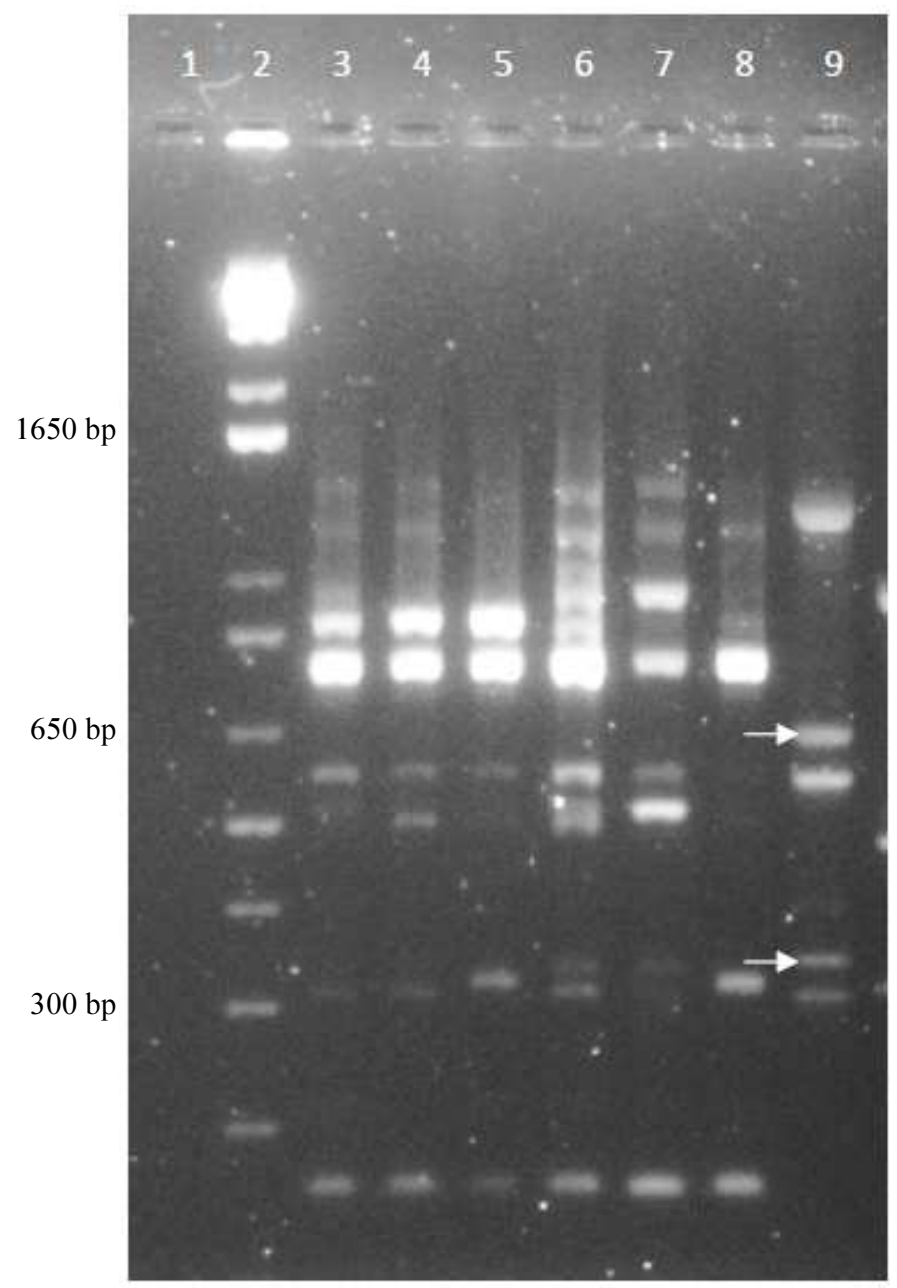

Fig. 8: Primer RAPD UBC 402 amplified profiles of genomic DNA from Betula papyrifera and Betula pumila in 2\% agorose gel; Where lane 1 is the blank and lane 2 the $1 \mathrm{~kb}+$ DNA ladder. Lane 3-8 represents amplified pooled B. pumila DNA from Sudbury and lane 9 is the amplified pooled B. pumila DNA from Wisconsin USA (lot number: 1819892). The arrow shows the population diagnostic band for B. pumila from Wisconsin (lane 9).

RAPD UBC 402 primer generated two markers of $\sim 675 \mathrm{bp}$ and $\sim 350 \mathrm{bp}$ that differentiated Betula pumila populations from Wisconsin from Sudbury's (Fig. 8).

All the observed Betula papyrifera diagnostic markers were observed in the St. Charles population. However, the diagnostic marker for Betula pumila was observed either in the populations from Wisconsin or the GSR.

In previous studies, Kalubi et al. (2015) identified an ISSR marker that differentiated red maple (Acer rubrum) populations from metal contaminated sites and uncontaminated areas in Northern Ontario. Likewise, Theriault et al. (2014) characterized two populationdiagnostic ISSR markers in B. papyrifera from Northern Ontario that showed difference between St. Charles population and other populations from the Greater Sudbury areas. This result along with the observations made in the present study suggested that B. papyrifera population from St. Charles represent a distinct population from other GSR populations which might be all from a common source. Since no-species diagnostic markers were detected in the present study, the validation of putative $P$. pumila $\times B$. papyrifera hybrids using molecular was not possible.

Thomson et al. (2015) reported that despite a high incidence of allele sharing among $B$. papyrifera, $B$. alleghaniensis and $B$. lenta, all of the species were significantly differentiated even within zones of sympatry using nuclear microsatellite markers. They identified putatively admixed individuals using Bayesian model-based clustering in their study. This theoretical classification of hybridity is usually not informative. Genomic in situ hybridization would be the most accurate approach to characterize putative hybrids and to determine the level of introgression between two species (Nkongolo et al., 2009; Silva and Souza, 2013).

For the present study, since B. pumila and $B$. papyrifera coexist in close proximity in GSR, the 
hybridization might result in the development of fertile or semi-fertile hybrids. Backcrossing of these progenies with the parents can then lead to introgression and creation of novel genotypes (Oberprieler et al., 2010). The other scenario described by Rieseberg and Willis (2007) is that hybrids may through karyotypic and ecological divergence or polyploidization become reproductively isolated from the parents resulting in limited gene flow among parental species. In fact, in some species, pollen competition can act as a partial reproductive barrier limiting the frequency of hybrid formation (Rieseberg et al., 1995; 1998; Lepais et al., 2009; Lepais and Gerber, 2011). This last alternative is unlikely in the GSR because of a large pollen production and the lack of pollination barriers between the two species and their hybrids in sampled areas. This is documented by large frequencies of hybrid genotypes.

\section{Conclusion}

In conclusion, this study revealed extensive introgression of B. papyrifera genes into B. pumila based on morphological characterization in the Greater Sudbury areas where these two species are present. ISSR and RAPD analyses confirmed a high level of polymorphic loci in populations from the two species making the development of species-specific molecular markers challenging. Population-diagnostic markers were identified between populations from different origins.

\section{Acknowledgement}

This study was supported by the Natural Sciences and Engineering Council of Canada (NSERC). Thanks to Dr. Gabriel Theriault for assistance with B. papyrifera sampling and processing.

\section{Author's Contributions}

Nastaran Moarefi: Conduct all the molecular work and data analysis.

Paul Michael: Monitor molecular experiences and data analysis

Peter Beckett: Coordinalre field sampling and hybrid identification.

Kabwe Nkongolo: Coordinate the project and wrote the manuscript.

\section{Conflict of Interest}

Authors declare that they have no conflict of interest.

\section{Compliance with Ethical Standards}

This article does not contain any studies with human subjects or animals performed by any of the authors.

\section{References}

Anamthawat-Jonsson, K. and A.T. Thorsson, 2003. Natural hybridisation in birch: triploid hybrids between Betula nana and B. pubescens. Plant Cell Tiss. Org., 75: 99-107.

Barnes, B.V., B.P. Dancik and T.L. Sharik, 1974. Natural hybridization of yellow birch and white birch. Forest Sci., 20: 215-221.

Blackmore, S., J.A.J. Steinmann, P.P. Hoen and W. Punt, 2003. The Northwest European pollen flora 65: Betulaceae and corylaceae. Rev. Palaeobot. Palynol., 123: 71-98.

DOI: $10.1016 / \mathrm{S} 0034-6667(02) 00156-2$

Brittain, W.H. and W.F. Grant, 1967. Observations on Canadian birch (Betula) collections at the Morgan Arboretum. IV. B. caeruleagrandis and hybrids. Can. Field Nat., 81: 116-127.

Clausen, K.E., 1962. Introgressive hybridization between two Minnesota birches. Silvae Genet., 11: 142-150.

Doyle, J.J. and J.L. Doyle, 1987. A rapid DNA isolation procedure for small quantities of fresh leaf tissue. Phytochem. Bull., 19: 11-15.

Froiland, S.G., 1952. The biological status of Betulaandrewsii A. Nels. Evolut., 6: 268-282.

DOI: $10.1111 /$ j.1558-5646.1952.tb01424.x

Grant, W.F. and B.K. Thompson, 1975. Observations on Canadian birches, Betula cordifolia, B. populifolia, B. papyrifera and B. x caerulea. Can. J. Bot., 53: 1478-1490. DOI: 10.1139/b75-181

Hao, W., S. Wang, H. Liu, B. Zhou and X. Wang et al., 2015. Development of SSR markers and genetic diversity in white birch (Betula platyphylla). PLoS ONE, 10: e0125235-e0125235.

DOI: 10.1371 /journal.pone.0125235

Ives, J.W., 1977. Pollen separation of three North American Birches. Arct. Alp. Res., 9: 73-80. DOI: 10.2307/1550410

Kalubi, K.N., M. Mehes-Smith, R. Narendrula, P. Michael and A. Omri, 2015. Molecular analysis of red maple (Acer rubrum) populations from a reclaimed mining region in northern ontario (Canada): Soil metal accumulation and translocation in plants. Ecotoxicology, 24: 636-647.

DOI: $10.1007 / \mathrm{s} 10646-014-1411-7$

Karlsdóttir, L., M. Hallsdóttir, A.T. Thórsson and K. Anamthawat-Jónsson, 2008. Characteristics of pollen from natural triploid Betula hybrids. Grana, 47: 52-59. DOI: 10.1080/00173130801927498

Lepais, O. and S. Gerber, 2011. Reproductive patterns shape introgression dynamics and species succession within the European white oak species complex. Evolution, 65: 156-70. DOI: $10.1111 /$ j.1558-5646.2010.01101.x 
Lepais, O., R.J. Petit, E. Guichoux, J.E. Lavabre and F. Alberto et al., 2009. Species relative abundance and direction of introgression in oaks. Mol. Ecol., 18: 2228-2242.

DOI: 10.1111/j.1365-294X.2009.04137.x

Les, D.H., 2017. Aquatic Dicotyledons of North America: Ecology, Life History and Systematics. 1st Edn., CRC Press, pp: 1334.

Little, E.L., 1979. Checklist of United States trees (native and naturalized). U.S. Department of Agriculture, Agriculture Handbook 541. Washington, DC, USA.

Mehes-Smith, M., K.K. Nkongolo and P. Michael, 2007. Genetic analysis of Pinus strobus and Pinus monticola populations from Canada using ISSR and RAPD markers: Development of genome-specific SCAR markers. Plant Syst. Evol., 267: 47-63. DOI: $10.1007 / \mathrm{s} 00606-007-0534-1$

Nkongolo, K.K., S.D. Haley, N.S. Kim, P. Michael and G. Fedak et al., 2009. Molecular cytogenetics and agronomic characterization of advanced generations of wheat $\mathrm{x}$ triticale hybrids resistant to Diuraphis noxia: Application of GISH and microsatellite markers. Genome, 52: 353-360. DOI: $10.1139 / \mathrm{G} 09-010$

Nkongolo, K.K., P. Michael and T. Demers, 2005. Application of ISSR, RAPD and cytological markers to the certification of Piceamariana, $P$. glauca and $P$. engelmannii trees and their putative hybrids. Genome, 48: 302-311.

DOI: $10.1139 / \mathrm{g} 04-118$

NOF, 2018. Northern Ontario Plant database. Northern Ontario Flora.

http://www.northernontarioflora.ca/description.cfm? speciesid $=1004634$

Oberprieler, C., A. Barth, S. Schwarz and J. Heilmann, 2010. Morphological and phytochemical variation, genetic structure and phenology in an introgressive hybrid swarm of Senecio hercynicus and S. ovatus (Compositae, Senecioneae). Plant Syst. Evol., 286: 153-166. DOI: 10.1007/s00606-010-0295-0

Reznicek, A.A., E.G. Voss and B.S. Walters, 2011. Michigan Flora online. University of Michigan.

Rieseberg, L.H., 1995. The role of hybridization in evolution: Old wine in new skins. Am. J. Bot., 82: 944-953. DOI: 10.1002/j.1537-2197.1995.tb15711.x

Rieseberg, L.H., S.J.E. Baird and A.M. Desrochers, 1998. Patterns of mating in wild sunflower hybrid zones. Evolution, 52: 713-726.

DOI: $10.2307 / 2411266$

Rieseberg, L.H. and J.H. Willis, 2007. Plant speciation. Science, 317: 910-914.

DOI: $10.1126 /$ science. 1137729
Silva, G.S. and M.M. Souza, 2013. Genomic in situ hybridization in plants. Genet. Mol. Res., 12: 2953-2965. DOI: 10.4238/2013.August.12.11

Sofiev, M., P. Siljamo, H. Ranta, T. Linkosalo and S. Jaeger et al., 2013. A numerical model of birch pollen emission and dispersion in the atmosphere. Descript. Emiss. Module. Int. J. Biometeorol., 57: 45-58. DOI: 10.1007/s00484-012-0532-z

Sofiev, M., P. Siljamo, H. Ranta and A. Rantio-Lehtim, 2006. Towards numerical forecasting of long-range air transport of birch pollen: Theoretical considerations and a feasibility study. Int. J. Biometeorol., 50: 392-402. DOI: $10.1007 / \mathrm{s} 00484-006-0027-\mathrm{x}$

Theriault, G., K.K. Nkongolo and P. Michael, 2014. Genetic and metal analyses of fragmented populations of Betula papyrifera (Marsh) in a mining reclaimed region: Identification of population-diagnostic molecular marker. Ecol. Evol., 4: 3435-3443. DOI: 10.1002/ece3.1195

Theriault G., K.K. Nkongolo, R. Narendrula and P. Beckett, 2013. Molecular and ecological characterisation of plant populations from limed and metal-contaminated sites in Northern Ontario (Canada): ISSR analysis of white birch (Betula papyrifera) populations. Chem. Ecol., 29: 573-585. DOI: 10.1080/02757540.2013.820715

Thomson, A.M., C.W. Dick, A.L. Pascoini and S. SelvaduraiDayanandan, 2015. Despite introgressive hybridization, North American birches (Betula spp.) maintain strong differentiation at nuclear microsatellite loci. Tree Genet. Genomes., 11: 101-101.

DOI: $10.1007 / \mathrm{s} 1$ 1295-015-0922-6

Thorsson, A.T., E. Salmela and K. Anamthawat-Jonsson, 2001. Morphological, cytological and molecular evidence for introgressive hybridization in Birsh. J. Hered., 92: 404-408. DOI: 10.1093/jhered/92.5.404

Tran, A., K.K. Nkongolo, M. Mehes-Smith, R. Narendrula and G. Spiers et al., 2014. Heavy metal analysis in red oak (Quercusrubra) populations from a mining region in northern Ontario (Canada): Effect of soil liming and analysis of genetic variation. Am. J. Environ. Sci., 10: 363-373. DOI: $10.3844 /$ ajessp.2014.363.373

Uchytil, R.J., 1991. Betula papyrifera. In: Fire Effects Information System. U.S. Department of Agriculture, Forest Service, Rocky Mountain Research Station, Fire Sciences Laboratory.

Vaillancourt, A., K.K. Nkongolo, P. Michael and M. Mehes-Smith, 2008. Identification, characterisation and chromosome locations of rye and wheat specific ISSR and SCAR markers useful for breeding purposes. Euphytica, 159: 297-306. DOI: $10.1007 / \mathrm{s} 10681-007-9492-5$ 
Viereck, L.A., C.T. Dyrness, K. Van Cleve and M. Joan Foote, 1983. Vegetation soils and forest productivity in selected forest types in interior Alaska. Can. J. Forest Res., 13: 703-720. DOI: 10.1139/x83-101

Woodworth, R.H., 1929. Cytological studies in the Betulaceae. I. Betula. Bot Gaz., 87: 331-363.

DOI: $10.1086 / 333945$
Mei, Z., C. Zhang, M.A. Khan, Y. Zhu and M. Tania et al., 2015. Efficiency of improved RAPD and ISSR markers in assessing genetic diversity and relationships in Angelica sinensis (Oliv.) Diels varieties of China. Electron. J. Biotechnol., 18: 96-102. DOI: $10.1016 /$ j.ejbt.2014.12.006 